\title{
Postgraduate Students' Learning Styles in Electronic and Presence Training in Shiraz University of Medical Sciences
}

\author{
Nasrin Shokrpoor ${ }^{1}$ \\ Shiraz University of Medical Sciences, Shiraz, Iran \\ Rita Rezaee \\ Shiraz University of Medical Sciences, Shiraz, Iran \\ Shekoofeh Nikseresht \\ Shiraz University of Medical Sciences, Shiraz, Iran
}

\section{Introduction}

Learning is a complex process in which there is an interaction among many factors including the student's motivation, teacher, learning material, etc. Today, development of virtual environments has necessitated different issues about learning to be considered in the classrooms run through modern approaches. The students should have enough motivation in the learning situation and the material has to be easily at hand. A common theory used nowadays is constructivist learning theory. In this theory, there is a focus on the learner's experiences in the learning process. However, the common approach to teaching is still teacher centered, practicing traditional courses and practices. This makes students passive. Teaching approaches have shifted from teacher-centered to student-centered learning in which the student's role as active learner is emphasized. The learning results depend on students and teacher's activeness and interest in the subject. Student's activeness in the learning process can be activated with such learning methods as group work, discussions and questionnaires [1].

E-learning is a new approach to teaching and learning, requiring educators to rethink about the way to conduct the evaluation of process and outcomes. It creates new variables, constraints, and issues, which fundamentally makes it different from face-to-face learning environments. In this approach, the roles of the professor, teacher, and student change and the necessary resources and infrastructures differ.

\footnotetext{
1 Corresponding Author
} 
Even the educational objectives differ in various students, professors, teachers, and institutions [2].

The role of the teacher in the online learning environment has changed dramatically from what it has been in the traditional environment. The teacher has to become a facilitator of knowledge and a mentor to the students [3].

There are several factors which affect the learning process. One of the most important factors is students' learning styles which students obtain by experience and learning and grasp the contents proportional to their learning style. Learning styles are different approaches and ways of learning.

Many learning styles have been developed to allow for learners to be categorised into a specific learner type. This learner type can then be used to provide the learner with suitable learning material, thus possibly enhancing their overall potential for learning [4].

The role of personal learning style is of great significance for learning process and outcome. In most elearning environments, all students are exposed to same exercises, discussions, delivery of content, depending on preference of institution or tutor.

"Personalization in e-learning is the use of technology and student information to tailor interactions between a tutor and individual students in a way that students achieve better learning outcomes". Studies on personalization in e-learning focus on two main aspects; the first being the management of learning materials and other information, and second on the learning process with a strong focus on the people involved in learning activities [5].

Therefore lectures and instructional designers should pay more attention to students' learning styles. They should identify students' learning styles and encourage them to learn by designing proper education interventions [6].

Multimodal learners are people who have more than one learning style. There are several models describing learning. One of the most popular learning style models is that of Kolb [7].

In Kolb's LSI, the students' learning style preference is measured in two bipolar dimensions.

The four positions on the two dimensions describe four learning modes, as shown in Figure 1:

“- Feeling (concrete experience)-perceive information. A high score in the concrete experience dimension represents a receptive experience-based 
approach to learning that relies on feeling-based judgments. Thus, people tend to be empathetic.

- Watching (reflective observation) - reflect on how it will impact some aspect of life. A high score in reflective observation indicates a tentative, impartial, and reflective approach to learning. Learners prefer learning situations such as lectures that allow the role of impartial objective observers.

- Thinking (abstract generalization or conceptualization) - compare how it fits into own experiences. A high score in abstract conceptualization indicates an analytical, conceptual approach to learning that relies heavily on logical thinking and rational evaluation. They learn best in authority-directed impersonal learningsituations that emphasize theory and systematic analysis.

- Doing (active experimentation) - think about how this information offers new ways to act. A high score in active experimentation indicates an active "doing" orientation to learning that relies heavily on experimentation. These individuals learn best when they can engage in such things as projects, homework, or group discussions [7, p.362]."

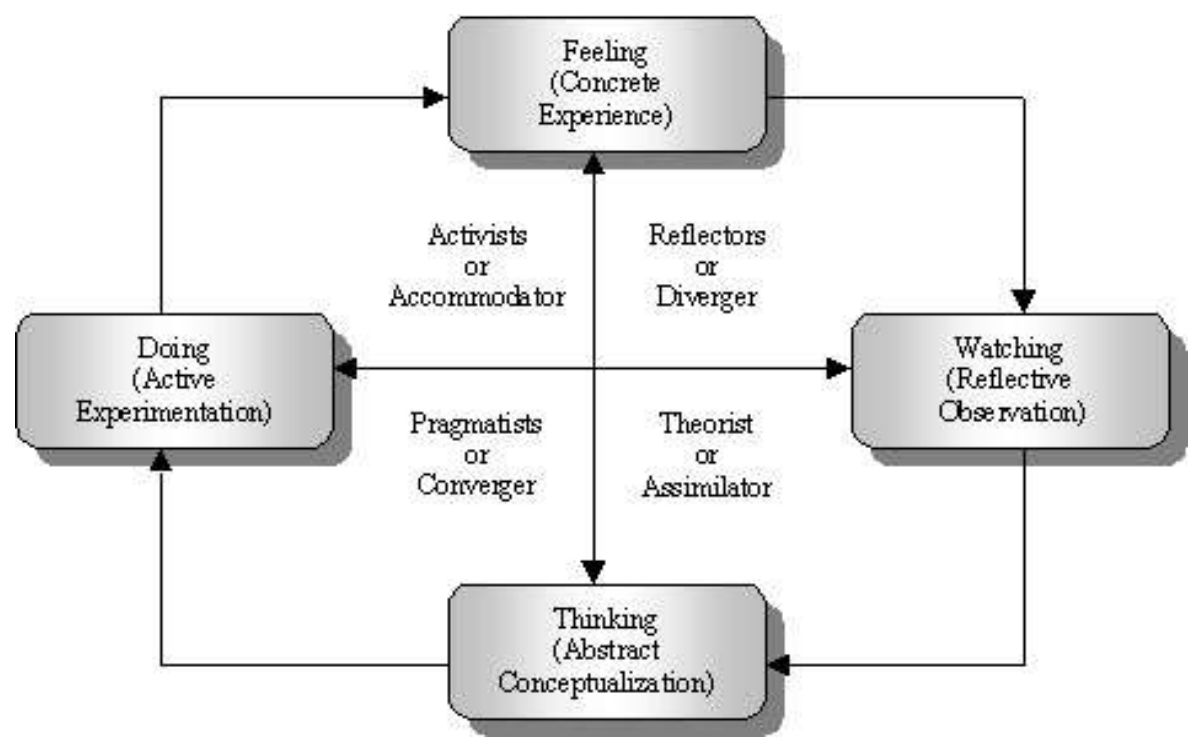

Figure 1.Kolb's Learning Style model

In this way, Kolb described four basic learning styles, as shown in Figure 1.

1. The converging style (abstract, active) relies primarily on abstract conceptualisation and active experimentation; is good at problem solving, decision making and the practical application of ideas; does best in situations like 
conventional intelligence tests; is controlled in the expression of emotion and prefers dealing with technical problems rather than interpersonal issues.

2. The diverging style (concrete, reflective) emphasizes concrete experience and reflectiveobservation; is imaginative and aware of meanings and values; views concrete situations from many perspectives; adapts by observation rather than by action; is interested in people and tends to be feeling-oriented.

3. The assimilating style (abstract, reflective) prefers abstract conceptualisation and reflective observation; likes to reason inductively and to create theoretical models; is more concerned with ideas andabstract concepts than with people; thinks it more important that ideas be logically sound than practical.

4. The accommodating style (concrete, active) emphasizes concrete experience and active experimentation; likes doing things, carrying out plans and getting involved in new experiences; good atadapting to changing circumstances; solves problems in an intuitive, trial-and-error manner; at ease with people but sometimes seen as impatient and 'pushy' [6].

\section{Method}

In this empirical survey, the samples of the research were 80 postgraduate students of Shiraz University of Medical Sciences who had enrolled in English language course in 2012. Half of them had attended the English classes by presence training and the rest of them had passed the course as e-learning training. A questionnaire based on Kolb's learning style inventory was used. The questionnaire included 12 questions which had four options: concrete experience, reflective observation, abstract conceptualization and active experimentation. Each of these options had their own scores among 12 questions which indicated four learning styles. Total score of each option indicated concrete experience learning stage (feeling), reflective observation learning stage (watching), abstract conceptualization learning stage (thinking), and active experimentation learning stage (doing), respectively. By subtraction of styles two by two which means subtraction of abstract conceptualization learning style from concrete learning style and subtraction of active experimentation learning style from reflective learning style, two scores were obtained. These scores were plotted on coordination system. The horizontal and perpendicular coordinates were reflective-active experimentation and concrete-abstract conceptualization learning style, respectively. These scores intersected at one of four quarters of coordination system which located the learning style. Each quarter indicated a learning style. They are the Accommodator, Diverger, Converger and Assimilator learning styles. The data were analyzed using SPSS software. 


\section{Results}

All students in e-learning and presence training courses filled the questionnaires. The number of female students in each group was higher than male ones. Also the number of single students was higher than married ones in the presence training group but it was vice versa in the e-learning group. The number of native and nonnative students was equal in the presence training group but the number of native student was higher in the e-learning group. The mean age of the students in the presence training and e-learning groups was $28 \pm 3.98$ and $29 \pm 4.47$, respectively and the mean score in the presence training and e-learning groups was $17.20 \pm 1.33$ and $16.9 \pm 1.002$, respectively. As shown in Table-1, the predominant learning style was assimilator style in the presence training group and converger style was the predominant learning style in the e-learning group. In this survey, two students of the presence training group and three students of the e-learning group had multiple learning styles.

Table 1. Students' Learning Styles in electronic and presence training

\begin{tabular}{|c|c|c|}
\hline \multirow{2}{*}{ teaching method } & E-learning & presence training \\
\cline { 2 - 3 } Tearning style & $\mathrm{N}(\%)$ & $\mathrm{N}(\%)$ \\
\hline The Accommodator & $3(7.5)$ & $7(17.5)$ \\
\hline The Diverger & $11(27.5)$ & $4(10)$ \\
\hline The Converger & $12(30)$ & $7(17.5)$ \\
\hline The Assimilator & $11(27.5)$ & $20(50)$ \\
\hline
\end{tabular}

\section{Conclusion}

As revealed in the results, most of the students in the presence training group had assimilator learning style; also most of the student in the e-learning group had converger learning style. The result of the survey conducted by Paul and Chris at University of Alberta in an attempt to determine the predominant learning style of medical students, general surgery residents and general surgeons showed that the predominant learning style of the medical students was the Assimilator and that for general surgery residents and general surgeons was the Converger. Also, the learning style, in the group in which medical students were trained in person, was 
consistent with the presence training learning style [8]. In another research which was conducted by Leila ValiZade et al. on learning style of nursing and midwifery students at Tabriz Medicine University, most of the students had the Accommodator and the assimilator learning styles [9]. Moreover, in a research was conducted by Azizi et al. at Qazvin Medical University it was revealed that students' learning styles were the Assimilator, the Converger, the Diverger and the Accommodator respectively and this result is completely consistent with the result of presence training style in this survey [10].

Based on a survey entitled as the relationship between personality traits and learning styles and the academic success of online students which was conducted by TabeBordbar at Payame-Noor University, the most learning style used by student was the Accommodator and the least used one was the Assimilator; this result is in contrast with our findings [11].

In this survey, it was concluded that learning styles in the e-learning group and presence training group were the Converger and the Assimilator, respectively. The greatest strength of those who has the Converger learning style is practical application of ideas and for those who has the Assimilator learning style is the ability to create theoretical models. We are not able to make a constructive comment on the predominant learning style of students who were trained in elearning group due to the small number of the studies in this field.

It is recommended that further studies should be conducted on different subject and fields. However, each training style and learning style has its own strong points but other weak aspects of learning should be taken into consideration. Lecturers should not let them stay weak and should use various teaching methods to provide learning opportunity for students to experience them. Furthermore, lecturers should select the best training style according to their students' learning style to reach the highest training efficiency.

\section{Acknowledgment}

This paper has been extracted from MSc thesis of Shokoufeh Nikseresht, MSc. student of medical education. The thesis was financially supported by Vicechancellor for research affairs of Shiraz University of Medical Sciences with grant number 6156. 


\section{References and notes:}

Kanninen E. Learning styles and e-Learning. Master's Degree Programme in Electrical engineering.

Tampere University of Technology Publications. 2008.

Mandinach EB. The development of effective evaluation methods for e-Learning: A concept paper and action plan. Teachers College Record. 2005; 107(8): 1814-1835.

Harden RM. E-learning and all that jazz. Medical Teacher. 2002; 24(2): 225-226.

Peter SE, Bacon E, Dastbaz M. Learning styles, Personalization and Adaptable e-Learning. INSPIRE. 2009; 77-87. ISBN 978-1-906124-22-9.

Bechter C, Esichaikul V. Using Kolb's learning style inventory for e-Learning personalizayion. IADIS international conference on cognition and exploratory learning in digital age. CELDA. 2008; 121-128.

Coffield F, Moseley D, Hall E, Ecclestone K. Learning styles and pedagogy in post-16 learning. A systematic and critical review. London: Learning and Skills Research Centre. 2004.

Bechter C, Esichaikul V. Catering for different learning styles in e-learning. LLC. 2010; 361- 374. Paul TE, Chris DG. Learning styles of medical students, general surgery residents, and general surgeons: implications for surgical education. BMC Medical Education. 2010; 10: 51.

Valizadeh L, Fathiazar S, Zamanzadeh V. Nursing and midwifery students' learning styles in Tabriz Medical University. Iranian Journal of Medical Education .2006; 6(2): 136139.

Azizi F, Khanzadeh A, Hoseini M. Survey of learning styles based on Kolb's model in Qazvin University of Medical Sciences. Iranian Journal of Medical Education.2001; 7:87.

Bordbar FB. The Relationship between personality traits and learning styles and the academic success of online students. MEDIA, 2012;3(2): 10-16. 


\title{
SUMMARY
}

\section{Postgraduate Students' Learning Styles in Electronic and Presence Training in Shiraz University of Medical Sciences}

\author{
Nasrin Shokrpoor \\ Shiraz University of Medical Sciences, Shiraz, Iran \\ RitaRezaee \\ Shiraz University of Medical Sciences, Shiraz, Iran \\ ShekoofehNikseresht \\ Shiraz University of Medical Sciences, Shiraz, Iran
}

In learning, as a complex process, there is an interaction among the student's motivation, teacher, learning material and several other factors. Today, the traditional classroom teaching is replaced with virtual environments where different issues about learning should be considered. The role of personal learning style is very important for learning process and outcome. This study aims at determining the students' predominant learning style in elearning training and presence training. 80 postgraduate students studying at Shiraz University of Medicine Sciences were divided into two equal groups and trained in two distinct methods, presence training and e-learning. They filled a questionnaire based on Kolb's learning style. Most of the students in the e-learning group had converger learning style. Therefore, lecturers should use various teaching methods at universities to provide a learning opportunity for students to experience them.

Keywords: learning, presence training, e-learning, learning styles 